\title{
pÿHow to dance Harlem Shake in Finland Creating a Video Project
}

\section{Ruismäki, Heikki}

2013

pÿRuismäki , H \& Ruokonen , I 2013 , ' How to dance Harlem Shake in Finland Creating a Video Project ' , The European Journal of Social \& Behavioural Sciences , vol. 7 , pp.

1244-1251 . https://doi.org/10.15405/ejsbs.104

http://hdl.handle.net/10138/233045

https://doi.org/10.15405/ejsbs.104

cc_by_nc_nd

publishedVersion

Downloaded from Helda, University of Helsinki institutional repository.

This is an electronic reprint of the original article.

This reprint may differ from the original in pagination and typographic detail.

Please cite the original version. 


\title{
The European Journal of Social \& Behavioural Sciences (EJSBS)
}

The European Journal of Social \& Behavioural Sciences (eISSN: 2301-2218)

\section{How to dance Harlem Shake in Finland - Creating a Video Project}

\author{
*Heikki Ruismäki ${ }^{\text {a*, Inkeri Ruokonen }}{ }^{\mathrm{a}}$ \\ ${ }^{a}$ Department of Teacher Education,University of Helsinki, Finland
}

http://dx.doi.org/10.15405/ejsbs.104

\begin{abstract}
The purpose of the study is to introduce the video project, Harlem Shake and questions that are related to its descriptions, editing, video making and pedagogy. The presentation is divided into three parts: planning, realization and evaluation. In the study, the use of videos in an educational context is considered. Research Questions are: How was the video project, Harlem Shake created at the University of Helsinki? What factors must be taken into consideration regarding music, pictures, and marketing? What statistical data can be concluded about the video? What are the pedagogical dimensions of the video project? What kinds of information and marketing-related factors must be taken into account when making videos? The Research method is a case study research where planning, realization and evaluation of a video project are analysed. Stimulated recall is used as an actual research method. The results show that a video project requires much work, planning, implementation and evaluation. The editor devises personal solutions to artistic and other questions. There are innumerable options. The making of the video gives many kinds of opportunities and has become one part of teaching. The videos are a part of the culture of children and adolescents.
\end{abstract}

(C) 2013 Published by C-crcs. Peer-review under responsibility of Editor or Guest Editor of the EJSBS.

Keywords: video production; video project; Harlem shake, editing; video clips; case study

\section{Introduction}

Making videos has become increasingly important in the lives of pupils and students. Scientific research has also increased recently (Cheng-Ting et al., 2011; Florez-Morris et al., 2010; Henderson et al., 2010; Hilton, 2011; Jarvis

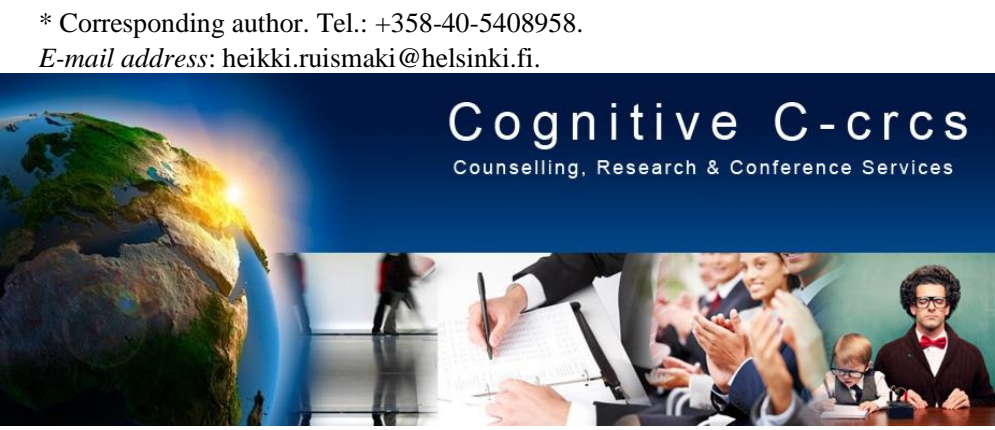


et al. 2011; Jensen et al., 2012.) It is easy to send videos to YouTube or Vimeo using simple applications and with a few mouse clicks. Basically, the whole world is the audience for video output when it is uploaded to the network. Countless numbers of different video materials are downloaded from the Internet every day.

Amateurs and enthusiasts also produce for the Internet more and more material that earlier was produced only by professionals in certain fields. This concerns the production of music, pictures, videos and different teaching materials. It provides meaningful opportunities and challenges. We can ask how a viewer can select the essential information

In principle, every photographer or video user can send videos to the Internet. Particularly the ease of sending videos makes it possible that on the Internet there are various kinds of video material. The simplest are video clips that have been sent by mobile phone, iPad or video camera and loaded to YouTube to be watched. On the other hand, the video can be edited and combined with almost unlimited number of photos, videos, clips, and music to create an artistic and ambitious video collage.

The purpose of this article is "to open" the world of the video maker. How does he or she design, execute and estimate the output that has been has made? What does the video maker think when making different decisions? Often video makers are interested in how their objects will be accepted. What objectives and goals a video maker set for the work? What kind of information do the outsiders see in the videos that are sent to YouTube? On the other hand, what kind of information does the video sender see when he/she creates a new account? These are questions that were asked in this video project taught to informant Mikko Halonen, who was the leader on this Harlem Shake video project.

\subsection{Memes}

It is the memes that are related to the Harlem Shake video product. The meme study is one topic of research. A meme is a concept that spreads via the Internet (Schubert, 2013). Further, the word meme was coined by Richard Dawkins in his 1976 book, The Selfish Gene as an attempt to explain the way in which cultural information spreads (Dawkins, 1989, 192). Internet memes are a subset of this, specific to the culture and environment of the Internet. Fads and sensations tend to grow rapidly on the Internet, because instant communication facilitates word of mouth transmission.

According to Dawkins $(1989,210)$, both the genes and memes spread despite whether they are useful for a person. For instance, the musical memes have been examined by Jan (2007). Dawkins (1993, 210) states that "melodies, thoughts, refrains et cetera" can be memes: "When giving the name to his invention, he wanted to have the noun which includes the idea of the unit of the conveying of the culture, in other words of the unit of the imitating". The Internet has further been a source for the creation and propagation of many new memes.

\subsection{Harlem Shake}

Harlem Shake is an Internet phenomenon where in similar videos people dance to the rhythm of the Harlem Shake tune by Baauer. The structure of the videos is nearly always similar: one person begins dancing and after some time others join to the dance swinging indefinitely. Usually the clothing of the participants is imaginative. Nearly 50,000 different Harlem Shake videos had been uploaded to the Internet by the end of February 2013. The reason the videos are so popular is their simplicity and brevity, about 40 seconds (Vaarama, 2013). Frilander (2013) says that the name that is heard in the videos has been borrowed from a dancing style that became popular at the beginning of the 1980s (Frilander, 2013).

According to Wikipedia, the Harlem Shake is technically very easy for fans to reproduce, as it consists of a single locked camera shot and one jump cut. Nonetheless, the simplicity of the concept allows fans considerable scope in creating their own distinctive variant and making their mark, while retaining the basic elements. In its simplest form, a video could be made with two people; a more sophisticated version might even involve a crowded stadium. Moreover, there is a level playing field for celebrities and fans alike, with no guarantee of success for either group. 
There is a strong vein of humour running through each video that is not dependent on language, further increasing the potential for it to spread virally (Berkowitz, 2013; Cochrane, 2013; Constine, 2013; Kosner, 2013).

Five teenagers from Queensland Australia established this meme, registered on YouTube as TheSunny CoastSkate (Allocca, 2013; Muir 2013). As more people replicated the original video and uploaded their own versions to YouTube, Harlem Shake rapidly became an Internet meme (Allocca, 2013; Lotan, 2013).

\subsection{Harlem Shake at the University of Helsinki}

Making and watching the Harlem Shake videos is a phenomenon in itself. Tens of thousands of videos were made in different parts of the world and they gained a large group of spectators fast since the 10 February 2013, even in Finland. A Harlem Shake video was also made at the University of Helsinki.

The Harlem Shake rapture was advertised on facebook. All students, teachers and other staff of the university, were invited to the event. Furthermore, they were asked to wear clothing in a Harlem Shake style. The Harlem Shake rapture was established as a group on facebook.

Mikko Halonen and his team filmed the Harlem Shake video with about 100 students and employees of the University of Helsinki. The shooting location was Minerva Plaza, at the Faculty of Behavioural Sciences at the University of Helsinki, Finland.

\section{Research design and purpose of the study}

The purpose of the study is to introduce the video project Harlem Shake and answer questions that are related to its description, editing, video making and pedagogy. The presentation and the interview are divided into three parts: planning, realization and evaluation. The study also considers how videos can be utilized in an educational context.

\subsection{Research questions and research methods}

- How the video project was named Harlem Shake created at the University of Helsinki?

- What does it mean to plan, realize and evaluate a video project?

- What factors must be taken into account regarding music, movie making, and marketing?

- What statistical data can be concluded about the video?

- What kinds of information and marketing-related factors must be taken into account when making videos?

The method was a case study research where planning, realization and evaluation of a video project are analysed. Stimulated recall is used as an actual research method. This research is a case study where the experiences of a leading person in the Internet environment are described. Our informant Mikko Halonen is a classroom teacher and works as an educational technology coordinator. He has had many kinds of experiences that would qualify him to make a video project at the University of Helsinki. In results all direct quotations the interviewees of are written in italic fonts.

Halonen has previously made a video production mainly for the University of Helsinki and the Finnish Federation of the Visually Impaired; often they have been short film projects or expert interviews. The videos of the University of Helsinki (2013) are available on the Vimeo channel: (https://vimeo.com/hufbs/). Otherwise, the videos have been made as a hobby ( http://www.youtube.com/user/FinAero ). A case study can be chosen as a method when a researcher wants to understand a phenomenon deeply and explore its context (see Yin, 2009; Merriam, 1998, 2009; Stake, 1995).

\section{Findings}

\subsection{Planning}

The person who had the idea for the rapture was Professor Kirsti Lonka. Our informant, Mikko Halonen from the Faculty of Education at the University of Helsinki was responsible for the practical realization and making of the 
video According to Halonen, there were many challenges: Event planning proceeded rapidly. The event wasn't planned, but was just advertised. It was already known that the Harlem Shake trend was in a way going down and that there were a huge number of videos available. At its best, or worst, videos were appearing at the rate of 100 copies per day. Information of the event was spread via different post lists, facebook and through other social media.

At the planning phase, facebook was searched for a pre-dancer and the students chose a suitable person among them. The students' choices were trusted, Halonen stated.

\subsection{Realization}

The video project was completed on 4 May 2013. There were about 100 students at the University of Helsinki, as well as some teachers who participated. In fact, the event went as planned and according to the script. When the planning was going on, it was decided what kind of shooting angles were wanted. Halonen described the process: There were three cameras on the floor and one camera was hanging from the ceiling. The choices of the cameras were decided quickly in one meeting while working together for a meeting. The students followed Halonen's instructions as they were given on facebook, and many students took various clothing to the Harlem Shake performance. They had all been invited to watch the previous videos of Harlem Shake. Halonen thought that, the more colour and life to the screen, the better it is.

The editing itself began soon after filming. They wanted the video to be spread around the world as soon as possible. Halonen said that they were already behind in the execution. He noted that hundreds of similar videos like Harlem Shake come to YouTube every day and it is more and more difficult to differentiate 'your own story'.

The researchers discussed the video with Halonen, and with the stimulated recall method he shared the following views: It was decided to make the video a little bit different in structure. We had this radio control aeroplane with a GoPro camera, and we filmed the approach by air towards the filming location. The aeroplane flies towards the glass wall in the Minerva room. At the beginning, a short neutral piece of music (only 7 seconds) played that suits Baauer's music. We wanted to differentiate because the meme too was nearly at the end. Therefore, we wanted to make a little bit better video. We also wanted to prove whose video it was: it was the whole University's video, not just our faculty's. We connected to the University Communications office and agreed that if the video would be shown on the University channel of the University, all faculties would be invited, and that is what we did.

It took about ten hours to make the whole video including one planning meeting, about one hour, filming about an hour, arranging the cameras about one and half hours, editing about five hours, for a total of 10 hours. We aimed to make the video as light as possible.

The video begins when Professor Lonka kind of gave a lecture and the students kind of listened. As a special effect, an explosion was made for the video: the logo of the University of Helsinki rises, and then smoke and sparks, and finally an explosion. Halonen describes the video further: One of the dancers begins to shake, and the others don't immediately join the dance. There are complete visual effects that are connected over the video. Part of the reason was also that we wanted to hide our own mistakes; positioning of the camera left an empty spot and it was filled. There was an empty spot, but then the logo of the University filled the empty spot. I got the idea of the logo, which starts to smoke, and at the end explodes. Then it continues in the Harlem Shake video format. The members of the audience changed their clothes when they heard the stroke and then join the dance. The pre-dancer stops when he/she hears the stroke. The audience is dressed as snowmen, penguins, pharaohs and other creatures.

If the upper camera would have been in a different position, the rhythm would have been more lively. The sparkling effect was projected on the screens and was seen as a pumping movement. So it looked more like a music video. Traditionally, the Harlem Shake video has been done with one camera.

The process contained two challenges: the filming had to be done very quickly in a certain place and time and there had to be a certain number of people in the audience. In this case, Halonen stated that there were about 100 people, which was suitable. 
Halonen likes challenges and in this video special effects, an explosion, smoke, and pumping of the picture in rhythm are exactly the things he wants to learn. It is typical for Halonen to develop his skills and challenge himself.

\subsection{Evaluation}

\subsubsection{How was the video received?}

The release time of the video was agreed to be at 12.4.2013. A little earlier a short teaser had been made of the video and the beginning of the video (was released 10.4.2013) had been filmed from an RC aeroplane a bit earlier. Halonen gave the following reasons for this procedure: "The meaning of this filming was to separate it from an 'ordinary' Harlem Shake video. And this was successful. For the first time, Halonen tested a stabilization of an aerial video. He will also use it later. According to Halonen and other persons who were involved in the event, it was interesting to see how the video was found and viewed on YouTube. Halonen says, at the moment the video has been watched 3,258 times on YouTube and 3,831 times on Vimeo.

However, the best way for marketing and spreading the video was facebook. The video team had also been considering how to maximize the video audience. At best, the original Harlem Shake (original army edition) video has been viewed almost 90 million times. By February 15, about 40,000 Harlem Shake videos had been uploaded, totalling 175 million views. The figures did not reach one million, but our own estimations were correct. If we had been the first, the figures would have been hundreds of thousands. Halonen speculated,

One of the main reasons was that the meme was already in the downturn. One reason was that we were from Finland. We chose Vimeo because we wanted the quality to be high and we managed to avoid the advertisements. Finally, the University of Helsinki wanted the video to appear on their YouTube channel, because they thought the video was very well done. We got 4,000 viewers. At the beginning, a bit worse videos had many viewers.

The research also brought out the benefits of social media for sharing various pieces of information especially among young students. Making the video taught Halonen many things that are related to video making, such as the way to meet personal challenges. Technically he learned from the stabilization of the picture, adding the special effects, making rhythm and pumping of the video, and filming with several cameras. Naturally, he also learned about communications.

The organization of the event was naturally "exciting", fun and interesting to those who participated in it. They received very positive feedback on the event and enjoyed a good spirit. Halonen felt that the participants received more than the viewers. He concluded, the good thing was that the students and teachers made something together and it clearly gave everyone enthusiasm and good feelings. It was a nice event to end the week.

\subsubsection{Statistical data from views and other factors}

YouTube also gives a means for analysing the videos more exactly. Only the owner of the account can see these. Naturally, we were also interested in these results. Viewers in YouTube were 3258, like 24, unlike 13. We could see only the Vimeo account, not the account that was maintained by the University.

The statistics on YouTube are much more comprehensive. Halonen noted,

I can't see at all statistics of YouTube. YouTube creates statistics of the persons who log into the account by Google. You can see which date or time or minute videos are watched. We can see furthermore gender distribution, where in the world the viewers are from, age group and so on. The statistics are researched carefully when it contains economic information. Our video has been most viewed on facebook (968 times), on Twitter (181), blogs and YLE. It is easy to share information through facebook. The publication was first announced on facebook. We can also see that the video was viewed 3,500 times in Finland, 77 times in the USA, 51 times in Sweden and 26 times in Great Britain. The video has been viewed or loaded in 56 countries. We got feedback that we were two months late in uplouding the video. Communication and advertising concentrated on facebook. Through facebook, the first link to the video was shared with the most viewers. 


\subsubsection{Video advertising, video and marketing}

Releasing of the video and the advertising, of course, raised the number of viewers. Halonen summarized the process, after releasing the video, the number of viewers increased. The first ones were likely the participants. The next rush was through the University communications. We got email lists, "think wall" and so on. The video wall in Minervatori also brought more viewers. When an advertisement was posted on the wall, the number of viewers increased. This was a good test for the future.

Halonen compares YouTube to Vimeo as a publishing channel for this kind of video. The advantage of YouTube is the larger audience and the advantages of Vimeo are the quality of video and the lack of advertisements. If something is produced on YouTube, there is no control over the advertising. He noted, Seventy euros per year is not much to pay for the Vimeo service when you are able to control the advertising.

We discussed the number of viewers and how that could have been considerably higher. Halonen analysed the situation as follows, With this video we were late about two months, the location of the country is not perfect. It is much more difficult to reach a large number of viewers like in the USA. Even if we were on TV in Finland, we wouldn't get hundreds of thousands of spectators.

If different societies are interested and link it to their own groups, the number of viewers will grow. If there were high quality content of videos, and the video could unite different societies, it is possible that the number of viewers would increase.

\section{Discussion}

This article described a video made of the Harlem Shake event in Finland and its planning, execution and evaluation. The event and the video taught this kind of short dynamic of a spectacle the results show that a video project requires much work, planning, implementation and evaluation. The editor makes many personal solutions during the process.

It is interesting to consider what kind of source material is available in the moving memes, and generally fresh phenomenon and their understanding. It is natural that any considerations, explanations, descriptions and other thoughts are first in the social media, in Twitter, on facebook, or in newspapers, television news, videos, etc. This research also showed that the scientific research does not easily assess ephemeral phenomena. However, the use of information technology, including videos is quite a topical issue among today's schoolchildren and students. According to Lonka (2013), in 2010 over 95\% of Finnish young people used ICT in their spare time, mostly for entertainment. Only $35 \%$ used it for learning at school.

Why do people send their own videos to the Internet? There must be many motives; for some it is an opportunity to earn or a desire to be present and be seen and probably a way to have influence. For someone else it could be a pure entertainment or a fun way to spend free time. Some people want to share their thoughts and discuss with friends. In any case, the number of videos on the Internet has increased dramatically.

Many outsiders may think that the Harlem Shake event was crazy; However, the feedback face-to-face has mainly been positive. Some of people thought that this kind of video was stupid and non-academic especially to appear on the University's official channel.

To ask a simple question, what did this video project teach? Halonen says: Doing and creating the video developed a feeling of common togetherness. The Harlem Shake video also raised the number of viewers on the Vimeo channel. After Harlem Shake, other videos were also found on the Faculty's new Vimeo channel.

This Harlem Shake video gathered together keen people from several faculties and they all had a fun time. The making of the video gives many kinds of opportunities and has become one part of teaching. The videos are a part of the culture of children and adolescents (see Ruokonen \& Ruismäki 2013). The interviewee experiences the making of videos as the factor, which includes fun and educational elements; it also increases the motivation and satisfaction of teaching. This is especially important in the Finnish school context in which it is important to raise school satisfaction. 


\section{References}

Allocca, K. (2013). (February 12, 2013). "The Harlem Shake has Exploded". Youtube via Blogspot. Retrieved February 15, 2013.

Anderson, J. (2013). Evaluating student-generated film as a learning tool for qualitative methods: Geographical "drifts" and the city. Journal of Geography in Higher Education, 37(1), 136-146.

Benedict, L., \& Pence, H. E. (2012). Teaching chemistry using student-created videos and photo blogs accessed with smartphones and two-dimensional barcodes. Journal of Chemical Education, 89(4), 492-496.

Berkowitz, J. (2013). "A brief history of internet phenomenon 'Harlem Shake'". FastCompany. (February 15, 2013).

Cheng-Ting Chen, \& Kuo-Chen Li. (2011). Action! —Boost students' English learning motivation with filmmaking project. Journal of Educational Technology Development \& Exchange, 4(1), 71-80.

Cochrane, G. (2013). "Viral fan videos propel Harlem Shake track into charts". BBC. (February 14, 2013).

Constine, J. (2013). "The Science Behind Why the Harlem Shake Is So Popular". Techcrunch. (February 19, 2013).

Dawkins, R. (1989). The Selfish Gene (2 ed.), Oxford University Press.

Dawkins, R. (1993) Geenin itsekkyys. (The Selfish Gene, 1989.) Suomentanut Kimmo Pietiläinen. Helsinki: Art House, 1993.

Florez-Morris, M. \& Tafur, I. (2010). Using video production in political science courses as an instructional strategy for engaging students in active learning. Journal of Political Science Education, 6(3), 315-319.

Frilander, A. (2013). Harlemin asukkaat: Harlem Shake ei ole Harlem Shake (the citizens of Harlem. Harlem Shake is not Harlem Shake. 20.2.2013. Nyt.fi. Retrieved 25.2.2013.

Henderson, M., Auld, G., Holkner, B., Russell, G., Seah, W. T., Fernando, A., \& Romeo, G. (2010). Students creating digital video in the primary classroom: Student autonomy, learning outcomes, and professional learning communities. Australian Educational Computing, 24(2), 12-20.

Hilton, G. (2011). Rehearsing for an audience: Students learning science through video production. International Journal of Innovation \& Learning, 9(3), 311-324.

Jan, S. 2007.The Memetics of Music. A Neo-Darwinian View of Musical Structure and Culture.

Jarvis, S. E., \& Han, S. (2010). Teaching citizenship: Student-led documentary film projects in the communication classroom Routledge. 325 Chestnut Street Suite 800, Philadelphia, PA 19106.

Jensen, M., Mattheis, A., \& Johnson, B. (2012). Using student learning and development outcomes to evaluate a first-year undergraduate group video project. CBE - Life Sciences Education, 11(1), 68-80.

Kosner, A. W. (2013) "The Present Shock Of The Harlem Shake". Forbes. (February 13, 2013).

Lonka, K. (2013). Mind the Gap project. Opettajan toimintaympäristö vuonna 2030. Teachers' environment in the Year 2030. http://www.slideshare.net/kirstilonka/educalonka2013 (retrieved 24.5.2013)

Lotan, G. (2013). "The Harlem Shake: Anatomy of a Viral Meme". Huffington Post. (March 5, 2013).

Merriam, S.B. (2009). Qualitative research: a guide to design and implementation. San Francisco: Jossey-Bass Publishers.

Muir, K. (2013). "Copycat shakers tap into worldwide video hit by Coast teens". Sunshine Coast Daily. Retrieved February 15, 2013.

Ruokonen, I. \& Ruismäki, H. (2013). Bridges of joy - a case study of the collaborative design learning process in the arts project of the university teacher students and children. Submitted in The European Journal of Social \& Behavioral Sciences.

Schubert, K. (2003). "Bazaar goes bizarre". USA Today. Retrieved 5.7.2003.

Stake, R.E. (1995) The art of case study research. Thousand Oaks, California: SAGE Publications.

Vaarama, V. (2013). Sotilaiden tanssivideolla jo yli 35 miljoonaa katsojaa. The soldiers dance video for more than 35 million viewers 25.2.2013. Yle Uutiset. Retrieved 25.2.2013. 
Yin, R. K. (2009). Case study research—design and methods. Fourth Edition California: SAGE.

\section{YouTube videos:}

YouTube. (2013). Harlem Shake (original army edition published 10.2.2013.). http://www.youtube.com/watch?v=4hpEnLtqUDg. Retrieved 26.5.2013.

YouTube. (2013). Broadcasting Ourselves. The official YouTube Blog. http://youtubeglobal.blogspot.fi/2013/05/heres-to-eight-great-years.html

YouTube (2013). University of Helsinki. https://vimeo.com/hufbs/harlemshake

YouTube (2013). University of Helsinki. https://vimeo.com/hufbs/minervatori

YoutuTube (2013). Ruismäki \& Halonen: FinAero (http://www.youtube.com/user/FinAero) 